\title{
Evaluating the Evaluators: Accrediting Knowledge and the Ranking of Political Science Journals*
}

\author{
James P. Lester, University of Oklahoma and Colorado State University
}

The nature of the scientific enterprise requires that we, as professionals in the discipline of political science, do all we can to improve the quality of our collective endeavors. This means that we must give serious attention to practical concerns about how to evaluate our departments, our scholars in the field, and our individual research. As Christenson and Sigelman (1985, 964) note, "not all ideas win equal acceptance, and neither do all the scholars who generate these ideas or all the institutions that house these scholars." Giles, Mizel, and Patterson (1989, 613) state, "publication in refereed journals is taken as a sine qua non for success in the discipline." It is generally accepted that tenure and promotion decisions, as well as merit salary increases, are heavily influenced by the quantity and quality of articles published in social science journals (Kawar, 1983; Giles, Patterson and Mizell, 1989). In addition, many library professionals are interested in the accreditation of knowledge for practical reasons. They assume that the quality of a journal affects user demand (Christenson and Sigelman, 1985).

This recognition has stimulated recent attempts to rank political science journals to assist decisionmakers in evaluating faculty (see, for example, Giles, Mizel, and Patterson 1989) and presumably to assist library personnel in journal selection. In the first generation of research on this issue, two approaches have been used: the "reputational" approach by Giles $(1975 ; 1989)$ and his colleagues; and the "impact" approach used by Christenson and Sigelman (1985).

The reputational approach surveys a representative sample of political scientists and asks them to evaluate selected journals. Respondents are typically asked to rate each journal in terms of the quality of its articles on a scale from 0 to 10 (i.e., poor to outstanding).

The impact approach relies on assessing political science journals by ranking them by the number of citations of articles published in a particular year, divided by the total number of articles published (i.e., the ratio of citations to citable items for a given journal; see Christenson and Sigelman, 1985).

Whether or not such attempts assist departmental chairpersons, faculty, and librarians depends, in part, on the credibility of the indices. While both of these approaches have been useful in the initial evaluation of a journal's status, they have limitations: they are based on "soft data" of rather limited utility or they are based on criteria too restricted for evaluating a journal's total significance.

\section{Some Problems with Previous Attempts to Rank Journals}

The approach used by Giles, Mizel, and Patterson, (1989) and reported here (see $P S$, September, 1989) is a useful first step in journal evaluation. However, it suffers from many of the same liabilities as the reputational approach used by Floyd Hunter (1953) in his study of community power. Specifically, a journal within the profession may have the reputation of having made a significant contribution to the discipline and yet it may have had very little influence in fact. ${ }^{2}$ In addition, such judgments may provide merely an aggregation of biases.

For example, the list of journals provided to the respondents contained few references to European political science journals. Those that were listed ranked low. Are there latent biases against European political science research within the American political science community? For political science to develop both conceptually and empirically, both American and European scholars should read each other's work. Otherwise, ethnocentrism could constrict the further development of the discipline.

Another indication of bias in the rankings presented by Giles, Mizel, and Patterson (1989) is the fact that the subfield of public administration/ public policy is viewed more negatively than any other subfield of the discipline. If we group journals by subfield using the categories identified by Brunk (1989) and compute an average score by subfield, the results suggest that journals publishing public administration/public policy research rate lowest of all the subfields of the discipline (see Table 1). On what basis do the respondents believe that public administration/public policy as a subfield is less valuable? This is particularly disturbing when we note that public policy studies have recently become the fastest-growing subfield in the discipline (Nagel, 1987).

In addition, the reputational approach is based on perceptual or soft data. In a similar type of questionnaire that sought to evaluate the best contributions in political science, Theodore Lowi (1983, 200-201) said that such subjectively based evaluations produce a response in which

\section{TABLE 1. \\ Political Scientists' Ratings of Selected Journals: Mean Scores}

$$
\text { Field of Inquiry }
$$
Mean Score

Political Theory $(\mathrm{N}=3)$

Comparative Politics $(\mathrm{N}=15)$

American Politics $(\mathrm{N}=16)$

International Politics $(\mathrm{N}=12)$

PA/Policy $(\mathrm{N}=8)$ 
"each respondent gives a presentation of self and the results will unavoidably present a false picture that serves poorly the goals of professional socialization." In other words, as Kuhn (1970) would say, there is no such thing as "immaculate perception." Finally, a reputational approach cannot be empirically verified. We have no way of knowing if the results are valid since they are not based on actual performance data.

The approach taken by Christenson and Sigelman (1985) goes further in generating a more empirical assessment of journal significance, yet it too represents an embryonic effort. The problem is that it does not go far enough in providing a systematic means to evaluate journals in the social sciences. Citations by themselves, do not define a journal's impact.

\section{Toward a Second Generation of Journal Evaluation: A Systems Approach}

The next generation of research in this area should include several dimensions that have heretofore been unexamined and that are assumed to tap multiple sources of a journal's significance.

In developing a more comprehensive means to evaluate political science journals, I suggest three categories of variables: (1) input measures; (2) decisional measures; and (3) outcome measures. These dimensions could be combined into an "index of journal quality" for ranking journals and for evaluating individuals for tenure and promotion decisions as well as merit salary increases.

For example, all of the indicators could be developed into a summary journal score by assigning an ordinal scale to each and then summing all the indicators into a composite score for each journal. Of course, some variables may be more important than others. Researchers will need to be sensitive to the issue of weighting some variables more heavily than others.

Input Measures. These measures include such things as the number of articles submitted to a journal. This variable assumes that better known journals have more articles submitted than do less prestigious journals. In addition, the acceptance or rejection rate of articles in a particular journal is a useful indicator of journal quality. These figures can be obtained from the journal editors.

Decisional Measures. These indicators are concerned with the composition of editorial boards and the decision-rules of particular journals. How are members selected for the editorial board? Are they leading scholars in the field? Are all fields represented? Is there a bias against a particular field on the editorial board? Are there ideological biases on the editorial board or among the reviewers? Is there a bias against innovative research? Moreover, editors exercise much discretion in accepting or rejecting journal articles for publication (Giles, Patterson, and Mizell, 1989). For example, how many negative reviews of an article are required before an article is rejected by the editor? Can the editor override the reviewers? How are reviewers selected? Does a reviewer have to have published in the journal before he (she) can review for that journal? How many reviews are required? If an article produces a split decision by the reviewers, how is this resolved? All of these factors are important in the review process, and they are the sine qua non of publication success in political science journals. Data on these categories of variables could also be obtained from surveys to the editors.

In addition, the timing of publication is essential to an article's impact. How long does it take for an article to progress through the journal's peer review system and get into print? Specifically, how long does it take from the initial reception of an article to the review process? How long before the reviewers reach a decision? How long does it take for the accepted article to move from copy-editing to page proofs to print? High quality articles in leading journals may have little citation impact if publication is delayed too long. On the other hand, articles in less prestigious journals may ultimately have more citation impact if they are published rapidly and disseminated widely.

Outcome Measures. These indicators are primarily concerned with the impact of the journals under evaluation. Are the journals widely circulated? How many copies are produced? How many issues are distributed per year? How many articles are published in each issue? Do the journals represent a narrow or a broad view of political science? Are they read by political science researchers, teachers, and/or practitioners? Are their articles widely cited? How frequently? A useful gauge of impact may be taken from the Social Sciences Citation Index. This was the approach advocated by Christenson and Sigelman (1985). Moreover, Hargens and Felmlee $(1984,686)$ suggested that "the number of citations to a scientist's work is often recommended as the best single indicator of scholarly recognition."

In our collective efforts to develop the means to evaluate the discipline, we have begun an important discussion about how to judge our departments, our scholars, and our research. It is now necessary to take the next step, a second generation of journal evaluation that goes beyond publication of subjective estimates. Assuming that we aspire to a genuine science of politics, we need to recognize that not all political science journals are equal and to continue the task of journal evaluation that began almost 15 years ago. I believe that the evaluation of political science journals can proceed constructively by developing a more comprehensive and systematic instrument, such as that begun here.

\section{Notes}

\footnotetext{
*The author wishes to thank Stephan Schmidt, department of political science, University of Linkoping, Sweden, and David R. Morgan, department of political science, University of Oklahoma, for their helpful comments on this paper.

1. This is not unique to political science, of course. See, for example, previous attempts to rank sociologists (Allison and Stewart, 1974), sociology journals (Glenn, 1971), departments of economics (Graves, Marchand, and Thompson, 1982), and economics journals (Liebowitz and Palmer, 1984; Moore, 1972).

2. The same thing may be said of individ-
} 
uals in the profession. On this point, see work by Robey (1982: 199).

\section{References}

Adams, W. C. 1983. "Reputation, Size, and Student Success in Public Administration/ Public Affairs Programs." Public Administration Review 43: 443-446.

Allison, Paul D. and John A. Stewart. 1974. "Productivity Differences Among Scientists: Evidence for Accumulative Advantage." American Sociological Review 39: 596-606.

Blair, Jeffrey H., William E. Thompson, Joseph V. Hickey, and Phillip L. Kelly. 1988. "Elitism Among Political Scientists: Subjectivity and the Ranking of Graduate Departments." PS: Political Science and Politics 21: 669-674.

Brunk, Gregory G. 1989. "Social Science Journals: A Review of Research Sources and Publication Opportunities for Political Scientists." PS: Political Science and Politics 22: 617-627.

Christenson, James A. and Lee Sigelman. 1985. "Accrediting Knowledge: Journal Stature and Citation Impact in Social Science." Social Science Quarterly 66: 964-975.

Giles, Micheal W. and Gerald C. Wright. 1975. "Political Scientists Evaluation of 63 Journals." PS: Political Science and Politics 8: 254-257.

Giles, Micheal W., David Patterson, and Francie Mizell. 1989. "Discretion in Editorial Decision-Making." PS: Political Science and Politics 22: 58-62.

Giles, Micheal W., Francie Mizell, and David Patterson. 1989. "Political Scientists Journal Evaluation Revisited." PS: Political Science and Politics 22: 613-617.

Glenn, Norval D. 1971. "American Sociologists' Evaluations of Sixty-Three Journals." American Sociologist 6: 298-303.
Graves, Phillip E., James L. Marchand, and Randall Thompson. 1982. "Economics Departments Rankings: Incentives, Constraints, and Efficiency." American Economic Review 72: 1131-1141.

Hargens, Lowell L. and Diane Felmlee. 1984. "Structural Determinants of Stratification in Science." American Sociological Review 49: 685-697.

Hunter, Floyd A. 1953. Community Power Structure. Chapel Hill, NC: University of North Carolina Press.

Kawar, Amal. 1983. "Criteria for Tenure and Promotion at Public Universities and Colleges in the West." PS: Political Science and Politics 16: 541-545.

Klingemann, Hans-Dieter, Bernard Grofman, and Janet Campagna. 1989. "The Political Science 400." PS: Political Science and Politics 22: 258-270.

Klingemann, Hans-Dieter. 1986. "Ranking the Graduate Departments in the 1980s: Toward Objective Indicators." PS: Political Science and Politics 19: 651-661.

Kuhn, Thomas. 1970. The Structure of Scien tific Revolutions. Chicago: University of Chicago Press.

Legge, Jerome S. and James Devore. 1987. "Measuring Productivity in U.S. Public Administration and Public Affairs Programs." Administration and Society 19: 147-156.

Liebowitz, S. J., and J. P. Palmer. 1984. "Assessing the Relative Impacts of Economics Journals." Journal of Economic Literature 22: 77-88.

McCormick, James M. and Lee Bernick. 1982. "Graduate Training and Productivity: A Look at Who Publishes." Journal of Politics 44: 212-227.

Moore, William J. 1972. "The Relative Quality of Economics Journals: A Suggested Ratings System." Western Economics Journal 10: 156-169.

Morgan, David R. and Michael Fitzgerald. 1977. "Recognition and Productivity Among American Political Science Departments." Western Political Quarterly 30: 342-356.
Morgan, David R., et al. 1981. "Reputation and Productivity Among U.S. Public Administration and Public Affairs Programs." Public Administration Review 41: 666-673.

Nagel, Stuart S. 1987. "Evaluating Public Policy Evaluation." Public Studies Journal: 16: 219-233.

Robey, John. 1979. "Political Science Departments: Reputation vs Productivity." PS: Political Science and Politics 12: 202-209.

Robey, John. 1982. "Reputation vs Citation: Who Are the Top Scholars in Political Science?"' PS: Political Science and Politics 15: $199-200$.

Roettger, Walter B. 1978. "Status and Stability: Reputation of American Political Scientists." PS: Political Science and Politics 11: 6-12.

Rudder, Catherine. 1983. "The Quality of Graduate Education in Political Science: A Report on the New Rankings." PS: Political Science and Politics 16:48-52.

Stehr, Steven A. 1979. "A Note on Publication Rates in IR Journals." International Studies Notes 6: 10-13.

Welch, Susan and John R. Hibbing. 1983. "What Do The New Ratings of Political Science Departments Measure?" $P S$ : Political Science and Politics 16: 532-540.

\section{About the Author}

James $P$. Lester is on sabbatical leave from the department of political science, Colorado State University. He was a guest researcher at the University of Linkoping, Sweden, during fall 1989 and a visiting professor at the University of Oklahoma during spring 1990. 